\title{
In situ bioremediation of South African coal discard dumps
}

\author{
AK Cowan Rhodes University, South Africa \\ HM Lodewijks Anglo American, South Africa \\ LM Sekhohola Rhodes University, South Africa \\ OG Edeki Rhodes University, South Africa
}

\begin{abstract}
Current rehabilitation of coal discard dumps remains a challenge due to reliance on topsoil for establishment of vegetation. Fungcoal has been developed as a viable and alternative strategy for rehabilitation of coal discard dumps and opencast spoils. Fungcoal exploits fungi-plant mutualism to achieve biodegradation of weathered coal, which in turn, promotes reinvigoration of soil components, grass growth and re-vegetation. The main objective of the present study was to determine the effect of different co-substrate materials as carbon donor to support Fungcoal-induced humic acid-like substance enrichment of coal discard at commercial scale. This was achieved by monitoring changes in physicochemical properties of the substrate after Fungcoal application over a three-year period. Results show that where Fungcoal was applied with weathered coal as the carbon donor, and in the absence of added topsoil, it suppressed acidification and salinisation of the coal discard substrate and promoted humic acid-like substance enrichment to support growth and establishment of annual and perennial grasses. In the absence of co-substrate or where highly oxidised coal discard was used as co-substrate, no humic acid-like substance enrichment of the substrate was observed, substrate $\mathrm{pH}$ declined, cation exchange capacity and electrical conductivity remained elevated, and re-vegetation failed. The potential of an in situ bioremediation strategy like Fungcoal as an alternative to topsoil is discussed.
\end{abstract}

\section{Introduction}

Coal mining companies are obliged by South African legislation governing mine closure to rehabilitate and return mined land to a viable post-mining state that caters to alternative land use and mitigates any deleterious environmental impact (Limpitlaw et al. 2005; Limpitlaw \& Briel 2015). The conventional approaches to rehabilitation of opencast spoil and discard coal dumps in South Africa involves use of topsoil for establishment of vegetation cover. Common practice is to deposit a soil layer of $30-100 \mathrm{~cm}$ as a clad, followed by addition of fertiliser prior to seeding using a mix of annual and perennial grass species. This process is termed phytoremediation and 'phytoremediation ex planta' remains the most widely applied on coal discard dumps (Salt et al. 1998). The principle is based on plant-driven bio-stimulation of naturally occurring rhizospheric microorganisms through mineralisation of root exudate, which serves as a simple carbon source followed ideally by, degradation of the carbonaceous waste material. Establishment of a healthy vegetative cover on fairly new coal discard dumps however remains a big challenge due to hostile conditions such as lack of the macro minerals nitrogen and phosphorus, acidity, high temperatures and toxic metal concentrations which are characteristic of coal discard dumps (Maiti 2007). It is therefore not surprising that remediation strategies in South Africa have traditionally relied on creating a soil microenvironment to facilitate plant growth.

The current approach to cladding of coal discard dumps and opencast spoil with topsoil does provide an ideal medium for seed germination, seedling establishment and subsequent plant colonisation. Unfortunately, this practice does not necessarily lead to degradation of the underlying carbonaceous waste and may indeed serve only to mask and delay impending environmental disaster. Also, use of topsoil depends heavily on a readily available and accessible source and/or the excavation and transportation of many tonnes of topsoil, 
both costly and environmentally unsound. Thus, soil formation remains one of the most important challenges in developing protocols for sustainable restoration of functional ecosystems in mined landscapes (Sourkova et al. 2005). Rehabilitation of opencast spoil and coal discard dumps should therefore focus on two aspects: 1) transformation of the carbonaceous waste to a soil-like material through abiotic and biotic weathering and; 2) successful vegetation cladding of the dump and/or opencast spoil.

Successful establishment of vegetation can positively influence the rate at which the degradation of carbonaceous waste occurs. However, a major difficulty in the practical bioremediation of low grade and waste coals is the inability of the procedure to bring metabolically active biocatalysts into direct contact with the discard coal substrate. Results from a number of studies indicate that oxidised carbonaceous waste, e.g. low rank weathered coal and coal discard, is a substrate for many mycorrhizal fungi and other microorganisms (Laborda et al. 1999; Klein et al. 2013; Sekhohola et al. 2013). Early work carried out in our laboratory showed, albeit under defined conditions, that Neosartorya fischeri (Division: Ascomycota) degrades both hard coal and coal discard (Igbinigie et al. 2008, 2010; Mukasa-Mugerwa et al. 2010; Sekhohola et al. 2014). Furthermore, unpublished data from small scale field trials (Kleinkopje Colliery Roofcoal Dump, Mpumalanga, South Africa) suggested the in situ manufacture of an organic rich soil-like material when the coal-degrading fungus Neosartorya fischeri, arbuscular mycorrhizal fungi (AMF), and Cynodon dactylon were introduced together with weathered coal as the carbon donor. In these trials, transformation of coal discard to a depth of $650 \mathrm{~mm}$ occurred within six years. Based on these results and other laboratory studies a bioprocess for the in situ cladding of coal discard dumps was developed and patented (Rose et al. 2010). This bioprocess is known as Fungcoal.

This paper examines some underlying principles of Fungcoal as a bioprocess technology for large-scale rehabilitation of coal discard dumps and focuses on the practical application and in particular, where, when, and how the technology can be applied (without using topsoil) to ensure successful rehabilitation. More specifically, Fungcoal was investigated to derive a protocol to ensure biological degradation and transformation of the carbonaceous substrate into a humic-enriched soil-like material capable of supporting vegetation. This was achieved at small-scale by examining the contribution of both sprigs and seed of Cynodon dactylon, substrate liming, AMF, and weathered coal as co-substrate for Neosartorya fischeri, to the in situ biodegradation of coal discard. Commercial-scale trials were used to determine the extent to which Fungcoal depends on weathered coal as a co-substrate and to further refine a protocol for practical application to ensure successful rehabilitation.

\section{Methodology}

\section{$2.1 \quad$ Small-scale trials}

To test and optimise the patented Fungcoal bioprocess an area $(50 \times 100 \mathrm{~m})$ at Kleinkopje Colliery (Kleinkopje Roofcoal dump, latitude $26^{\circ} 1^{\prime} \mathrm{S}$; longitude $29^{\circ} 14^{\prime} \mathrm{E}$ ) was selected for a small-scale field trial (Figure 1). Individual plots $(20 \times 20 \mathrm{~m})$ were positioned along the contour of the aspect to minimise cross-contamination and the site was fenced to reduce grazing. Plots were rip ploughed, Aqualime (Prescription Fertilisers (NZ) Ltd) applied at a rate of $25 \mathrm{t} / \mathrm{ha}$ and where specified, weathered coal (sourced from the No 2 Seam, Kromdraai Section, Landau Colliery) applied at $750 \mathrm{t} / \mathrm{ha}$ and disced to a depth of $200 \mathrm{~mm}$. To each plot, limestone ammonium nitrate (LAN 28, Omnia, Bryanston, South Africa), containing $28 \% \mathrm{~N}$ and $5 \% \mathrm{Ca}$, was then applied at a rate of $30 \mathrm{~kg} / \mathrm{ha}$ using a lime spreader and irrigated using mine water. Thereafter an inoculum containing the AMFs, Glomus clarum, Paraglomus occultum, Gigaspora gigantea and Glomus mossea at $75 \mathrm{~kg} / \mathrm{ha}$ (Mukasa-Mugerwa et al. 2010), was applied. Soil-grown sprigs sourced from elsewhere on the mine were hand planted in plots 1 and 2, while plots 3, 4 and 5 were broadcast with seed of the perennial grass, Cynodon dactylon. The coal degrading fungus Neosartorya fischeri strain ECCN 84 was applied to a $100 \mathrm{~m}^{2}$ area in plot 3. The trial was initiated in the September 2006, re-vegetation was recorded annually in mid-summer by photograph, and physicochemical analysis of the substrate conducted in March 2013. 


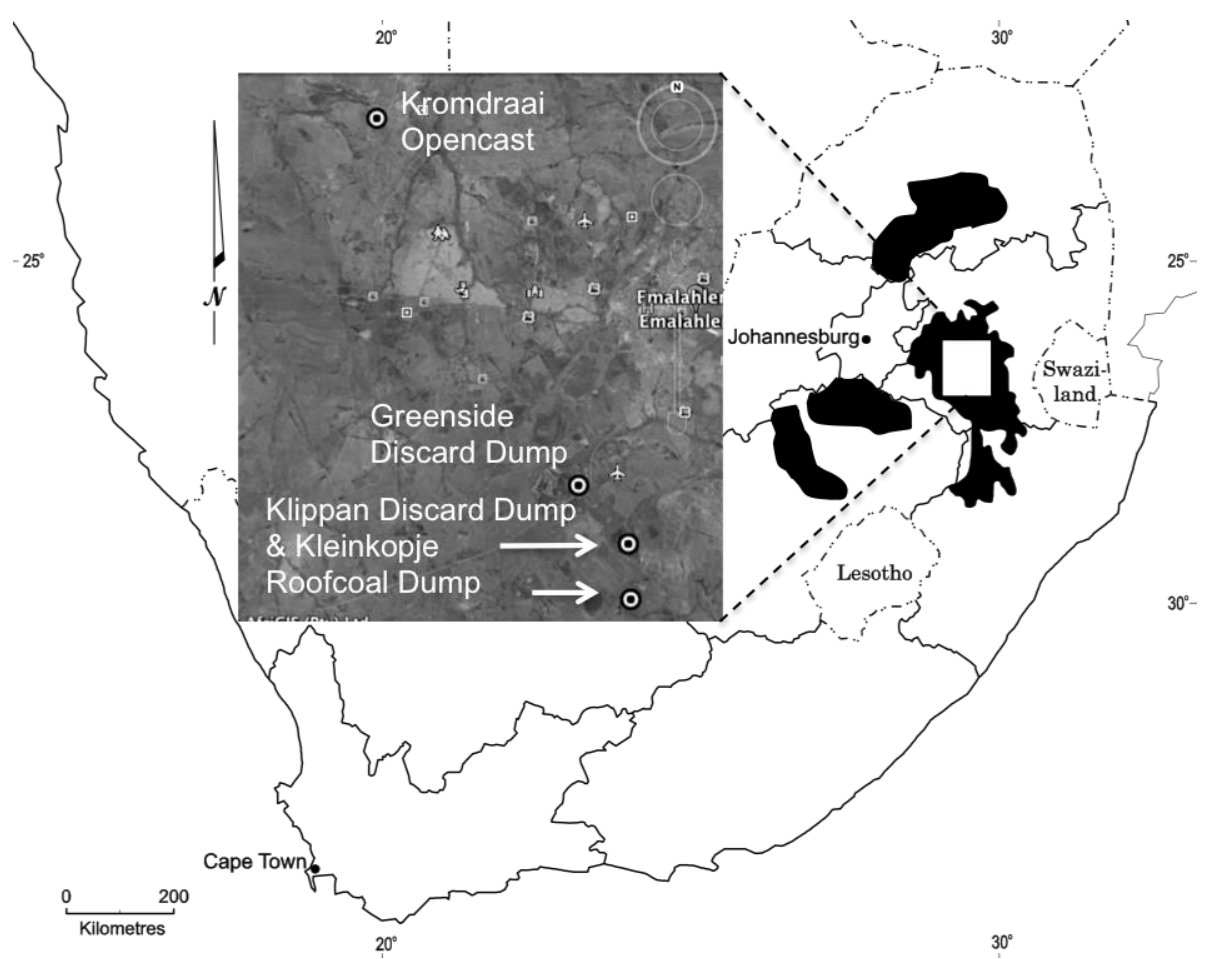

Figure 1 The location of the study area in the Emalahleni coalfields of South Africa. Inset: Google Earth image showing location of Kromdraai Opencast (Landau Colliery), Greenside Discard Dump (Greenside Colliery), Klippan Discard Dump and Kleinkopje Roofcoal Dump (Kleinkopje Colliery)

\subsection{Commercial-scale trials}

To determine the extent to which the Fungcoal process depends on the supply of suitable weathered coal and/or suitable weathered discard as the major carbon donor to achieve both myco- and phyto-remediation, large-scale commercial trials were initiated. Coal discard dumps located at Kleinkopje Colliery (Klippan Dump, latitude $25^{\circ} 60^{\prime} \mathrm{S}$; longitude $29^{\circ} 14^{\prime} \mathrm{E}$ ), Greenside Colliery (Greenside Dump, latitude $25^{\circ} 57^{\prime} \mathrm{S}$; longitude $29^{\circ} 11^{\prime} \mathrm{E}$ ) and Landau Colliery (Kromdraai opencast, latitude $25^{\circ} 46^{\prime} \mathrm{S}$; longitude $29^{\circ} 4^{\prime} \mathrm{E}$ ), in the Emalahleni Coalfield of South Africa were selected (Figure 1). These dumps are typically $1 \mathrm{~V}: 5 \mathrm{H}$ and $50 \mathrm{~m}$ in height and receive summer rainfall in the range 696-1,032 $\mathrm{mm}$ with mean daily minimum and maximum temperatures of 15 and $27^{\circ} \mathrm{C}$, respectively. The Greenside and Klippan waste dumps are composed of compacted coal discard (a mix of coarse material of varying particle sizes between $150 \mu \mathrm{m}$ to $150 \mathrm{~mm}$ ), while Kromdraai opencast consists of a mix of opencast spoil and highly weathered coal material.

Four 0.8-1 ha blocks on the south-facing aspect of each discard dump were cleared, demarcated, the surface rip ploughed and dolomitic lime applied at a rate of $5 \mathrm{t} / \mathrm{ha}$. No co-substrate was used on Klippan discard dump. Highly oxidised coal discard, obtained from the Clydesdale waste dump, was used as co-substrate on the Greenside discard dump and applied to 0.8 ha blocks to give a layer of either 10 ( $50 \%$ Fungcoal) or $20 \mathrm{~cm}$ (100\% Fungcoal). For Kromdraai opencast, weathered coal was applied at either 50 (50\% Fungcoal) or $100 \mathrm{t} /$ ha (100\% Fungcoal). Where specified, fungal inoculum containing Neosartorya fischeri strain ECCN 84 and Mycoroot, a propriety mix of AMFs, in the ratio $0.5 \mathrm{~g}$ ECCN 84:25 kg Mycoroot (Mycoroot Pty Ltd., Grahamstown, South Africa) was applied at rates of either 37.5 ( $50 \%$ Fungcoal) or $75 \mathrm{~kg} / \mathrm{ha}$ (100\% Fungcoal). Superphosphate (10.5\%) and 2:3:2 (22\%) + 0.5\% Zn (supplied by Dust \& Erosion Control CC., Heidelberg) was then applied at rates of $30 \mathrm{~kg} / \mathrm{ha}$ and $1 \mathrm{t} / \mathrm{ha}$, respectively. Fungcoal material containing fertiliser and the fungal inoculum was then disked into the substrate or spoil using a disc set at $300 \mathrm{~mm}$. Untreated controls (i.e. with and without co-substrate and fungal inoculum) and equal sized mine standards (i.e. the current rehabilitation protocol specific for that mine) were included for each trial as references. Typically, the mine standard involved applying a $30-500 \mathrm{~cm}$ clad of topsoil, followed by fertilisation using superphosphate 
$(10.5 \%)$ and 2:3:2 (22\%) $+0.5 \% \mathrm{Zn}$ applied at rates of $30 \mathrm{~kg} / \mathrm{ha}$ and $1 \mathrm{t} / \mathrm{ha}$, respectively. Experimental blocks on Klippan and Greenside discard dumps and the respective mine standards were seeded using a mix of Cynodon dactylon, Eragrostis tef, Chloris gayana, Pennisetum clandestinum and Paspalum notatum (10:1:3:2:4) applied at $20 \mathrm{~kg} / \mathrm{ha}$. For Kromdraai opencast, seed of Digitaria eriantha, Chloris gayana, Eragrostis tef, and Medicago sativa (5:5:4:2) was applied at $20 \mathrm{~kg} / \mathrm{ha}$. Irrigation was by natural precipitation. Due to mine regulation and existing contracts all operations relating to trial layout were carried out by either Fraser Alexander Bulk Mech. Pty. Ltd. (Greenside and Klippan discard dumps) or Dust and Erosion Control CC (Kromdraai opencast spoil).

\subsection{Sampling and physicochemical analysis}

Sampling was by complete randomised design. For sampling, at each of the intervals specified in the results, the small-scale plots and the 1 ha blocks were divided into quadrants and a total of twenty allocated for sampling using a random number generator. Similarly, each of these smaller blocks was divided further into $1 \times 1 \mathrm{~m}$ units and sampling points assigned using a random number generator $(\mathrm{n}=4$ for small-scale plots; $\mathrm{n}=20$ for 1 ha blocks). Substrate samples $(500 \mathrm{~g}$ ) from a depth of 30-50 cm were collected using an auger, thoroughly mixed and transported to the laboratory in sealed zip-lock bags. Prior to analysis, samples were dried at $50^{\circ} \mathrm{C}$ for $24 \mathrm{~h}$ to a constant weight and pulverised (HERZOG Maschinenfabrik GmbH Co., Osnabrück, Germany).

Electrical conductivity (EC) and $\mathrm{pH}$ were determined for each sample using deionised water in $1: 1$ and 1:5 substrate:solution ratios respectively using the protocols described by Rayment and Higginson (1992). For each 1 ha block, composite homogenous sub-samples were prepared by combining $5 \mathrm{~g}$ of substrate from each of five randomly selected substrate samples and used to determine ash content, elemental composition, cation exchange capacity (CEC), and humic acid- and fulvic acid-like substance concentration. Elemental carbon, nitrogen and sulphur content of substrate samples were determined without further sample preparation using an elemental micro-analyser (Vario MICRO cube V1.6.2, Elementar Analysensysteme $\mathrm{GmbH}$, Germany) operated according to the manufacturer's specifications. For determination of ash content, substrate samples $(1 \mathrm{~g})$ were combusted at $900^{\circ} \mathrm{C}$ for $5 \mathrm{~h}$ using a Carbolite muffle furnace (Carbolite Limited, UK) and the residue expressed as weight percentage of the sample.

Measurement of CEC was by the $\mathrm{BaCl}_{2}$ compulsive exchange method (Ross 1995) and the protocol used was as described by Ross and Ketterings (2011).

Humic acid- and fulvic acid-like substances were extracted using the method described by Janos (2003). To $2.5 \mathrm{~g}$ of oven dried material was added $0.1 \mathrm{M} \mathrm{NaOH}$ to final volume of $100 \mathrm{~mL}$ and the mixture extracted on a rotary shaker for $24 \mathrm{~h}$, centrifuged (Eppendorf Benchtop Centrifuge $5810 \mathrm{R}$, Drücken, Germany) at $1252 \times \mathrm{g}$ for $90 \mathrm{~min}$ at $10^{\circ} \mathrm{C}$, and the supernatant and pellet separated. The $\mathrm{pH}$ of supernatant was adjusted to $<\mathrm{pH} 1$ using conc. $\mathrm{HCl}$ and the humic-like substances precipitated by centrifugation and the pellet re-suspended in $0.1 \mathrm{M} \mathrm{NaOH}$. Humic-like substances in the re-suspended pellet were quantified by interpolation from standard curves for Leonardite-derived humic acid and peat-derived fulvic acid (purchased from International Humic Substance Society, St. Paul, MN) after determining the absorbance (Thermo Spectronic Aquamate, ThermoFisher Scientific, Waltham, MA) at 240 and $250 \mathrm{~nm}$, respectively. Confirmation of humic- and fulvic-like substances was by Fourier Transform Infrared spectroscopy using a PerkinElmer Spectrum 100 instrument (PerkinElmer, Waltham, MA) with spectral range of $25,000-100 \mathrm{~cm}^{-1}$ and refractive index of 2.4 and $2.01 \mu$ depth of penetration.

\subsection{Statistical analysis}

All data are reported as the standard error (SE) of the means and where specified, results were analysed by one way analysis of variance using Sigma Plot version 11 (Systat Software Inc.) and significant differences between measurements for each treatment determined (Holm-Sidak method; $\mathrm{P}<0.05$ ). 


\section{$3 \quad$ Results}

The results in Figure 2 present a summary of the substrate physicochemical properties after six seasons from small-scale trials carried out at Kleinkopje Roofcoal dump. Indeed, analysis of the substrate from each of the five treatments revealed that the patented Fungcoal bioprocess (Treatment 3) yielded a substrate with near neutral $\mathrm{pH}$, elevated CEC, and significantly higher amounts of humic acid-like substance. The increase in humic acid-like substance concentration occurred concomitant with a measureable decline in substrate carbon, nitrogen, and sulphur and a significant reduction in fulvic acid-like compounds. The increase in humic acid-like substances, and decrease in fulvic acid-like substances, within the substrate was significantly less without prior liming and where sprigs of Cynodon dactylon rather than seed were used. This observation was mirrored in the density of the aboveground vegetation, which was substantial (near $100 \%$ canopy cover; $>40 \%$ basal cover) and with increased species diversity (data not shown).
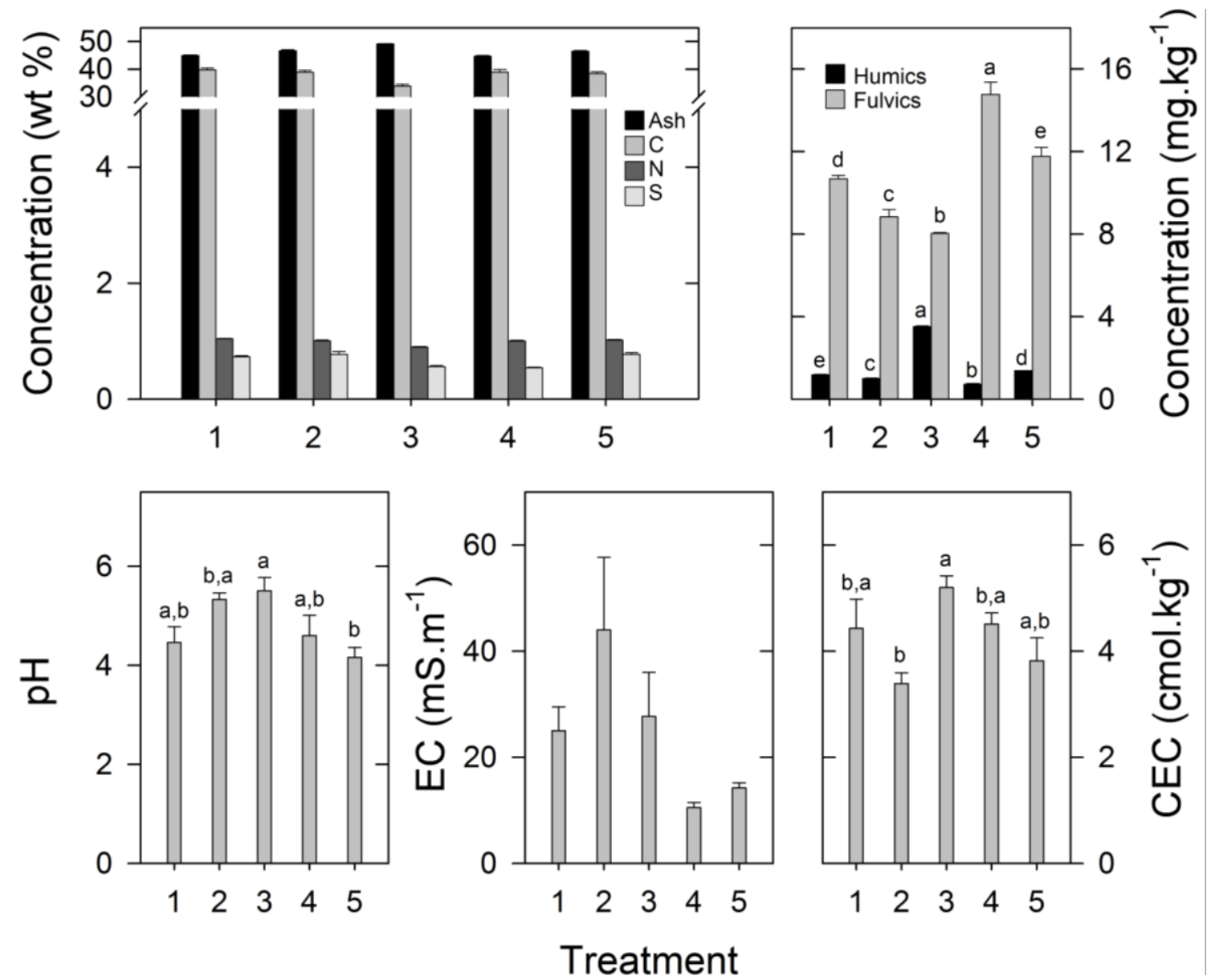

Figure 2 Substrate physicochemical characteristics at small-scale for optimisation of the Fungcoal rehabilitation bioprocess. Trials were initiated in the spring of 2006 on the Kleinkopje Roofcoal dump and substrate assayed in March 2013. Treatments: $1=$ lime + weathered coal + sprigs + AMF inoculum; 2 = lime + sprigs; $3=$ lime + weathered coal + seed + AMF inoculum + Neosartorya fischeri; $4=$ lime + seed + AMF inoculum; 5 = weathered coal + seed + AMF inoculum. Data are presented as mean $\pm S E(n=4)$ and bars with different letters are significantly different $(p>0.05)$

The above small-scale trial confirmed that the Fungcoal bioprocess, which comprises a consortium containing a coal degrading fungus and AMFs in combination with weathered coal (as co-substrate) and a phyto-biocatalyst(s) such as Cynodon dactylon, enhances the humic acid-like substance content of the substrate to support re-vegetation and does so without the need for added topsoil. 
The potential to use Fungcoal for bioremediation, augmentation of decompaction, and self-cladding of discard dumps prompted commercial scale trials and coal discard and opencast spoil were selected as test substrates. Fungcoal was applied with and without the weathered coal co-substrate, and, a highly oxidised waste coal was tested as an alternative co-substrate. Results to date are summarised in Figures 3 and 4.
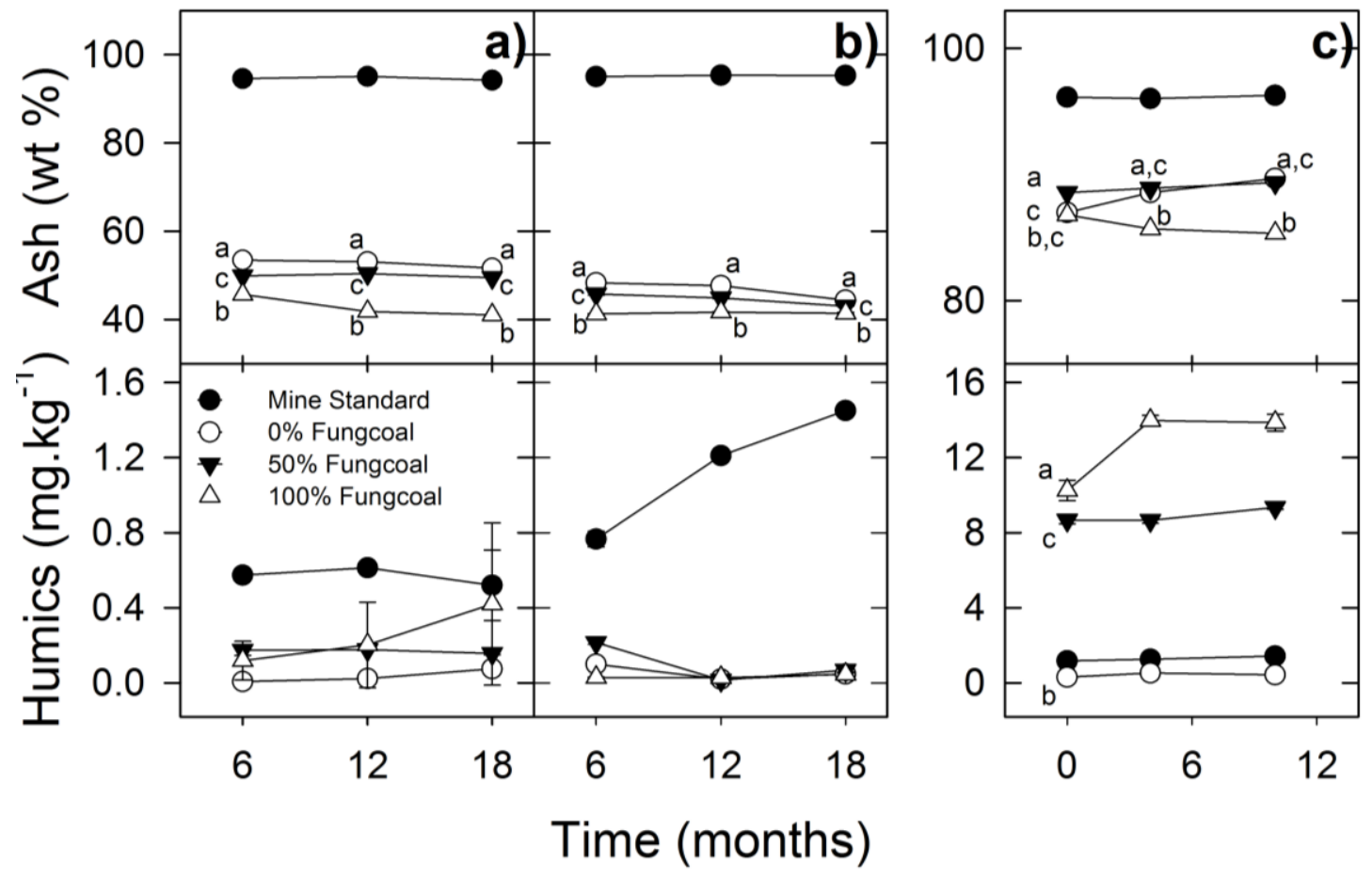

Figure 3 Time course illustrating the effect of co-substrate on ash and humic acid-like substance concentration in the presence of 0,50, and 100\% Fungcoal: (a) Klippan dump (Kleinkopje Colliery) no co-substrate; (b) Greenside dump (Greenside Colliery) with highly oxidised coal discard co-substrate; and, (c) Kromdraai opencast (Landau Colliery) with weathered coal as co-substrate. Trials were initiated in September 2011 (Klippan and Greenside dumps) and May 2012 (Kromdraai opencast) and the data presented as the mean $\pm S E(n=5)$. Data points followed by different letters are significantly different $(p>0.05)$

Site establishment and baseline sampling of the large-scale blocks was concluded in September 2011 (Klippan and Greenside discard dumps) and May 2012 (Kromdraai opencast), with further sampling in March 2012, September 2012, February 2013, and February 2014. Analysis of the discard substrate from Klippan (Figure 3(a); without co-substrate), Greenside (Figure 3(b); highly oxidised waste coal co-substrate) and Kromdraai (Figure 3(c); weathered coal co-substrate) within 18 months of application confirmed, not unexpectedly, that Fungcoal treatment significantly reduced substrate ash content, that this was concentration dependent, and greatest for $100 \%$ Fungcoal. No significant change in humic acid-like substance concentration was detected for substrate treated with either 50 or $100 \%$ Fungcoal in the absence of a co-substrate (Figure 3(a); Klippan discard dump) or when a highly oxidised waste coal (Figure 3(b); Greenside discard dump) was used as co-substrate. Somewhat surprising, and yet to be explained, was the observed increase in humic acid-like substance concentration in topsoil substrate from the Greenside Discard Dump mine standard which contrasted with observations for topsoil substrate from the Klippan Discard Dump mine standard (cf. Figures $3(a)$ and (b)).

Weathered coal as a co-substrate supported the Fungcoal bioprocess on Kromdraai opencast and substrate from both the 50 and $100 \%$ treatments demonstrated a substantial increase in humic acid-like substance concentration. Indeed, the content of humic acid-like substances for $100 \%$ Fungcoal treated opencast spoil increased to $\pm 14 \mathrm{~g} \cdot \mathrm{kg}^{-1}$ within four months (Figure 3(c)). This increase was less marked and protracted in substrate treated with $50 \%$ Fungcoal. As expected, substrate from the mine standard revealed humic acid-like substance levels similar to 0\% Fungcoal (Figure 3(c)). 

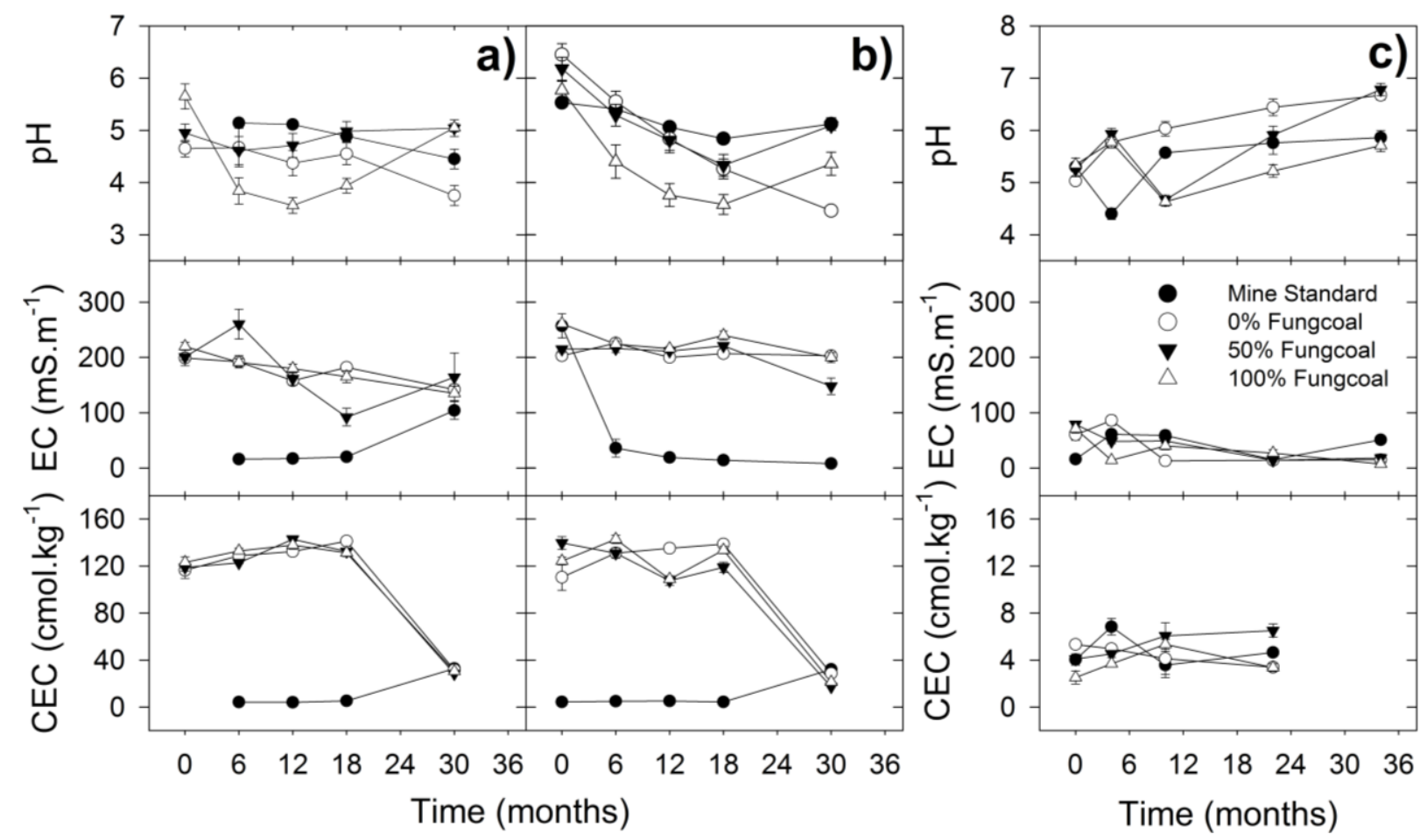

Figure 4 Time course illustrating the effect of co-substrate on substrate $\mathrm{pH}$, electric conductivity (EC), and cation exchange capacity after treatment with 0,50 , and $100 \%$ Fungcoal. See Figure 3 for details on trial set-up. Data presented as the mean \pm SE $(p>0.05)$

Substrate $\mathrm{pH}, \mathrm{EC}$, and $\mathrm{CEC}$ for each of the three commercial scale trials is presented in Figure 4. As expected, EC and CEC of substrate from discard treated without a co-substrate (Figure 4(a)) and a highly oxidised waste coal co-substrate (Figure 4(b)) were similar for 0, 50, and 100\% Fungcoal. Without co-substrate, EC declined gradually from \pm 200 to about $140 \mathrm{mS}^{-1} \mathrm{~m}^{-1}$, whereas discard treated with a co-substrate of highly oxidised waste coal had sustained EC of $\pm 200 \mathrm{mS}^{-1} \mathrm{~m}^{-1}$. By comparison, substrate CEC of discard appeared unaffected by the highly oxidised waste coal co-substrate. Furthermore, the temporal change in $\mathrm{pH}$ of substrate from discard treated with or without this co-substrate and Fungcoal at 0, 50, and $100 \%$ was similar. Thus, transient declines in substrate $\mathrm{pH}$ were observed after 50 and $100 \%$ Fungcoal treatment that appeared to depend on Fungcoal application rate (Figures $4(\mathrm{a})$ and (b)). Without Fungcoal, i.e. $0 \%$, substrate $\mathrm{pH}$ of discard treated with or without highly oxidised waste coal co-substrate continued to decline. Neither Klippan nor Greenside discard treated with or without a highly oxidised waste coal co-substrate and Fungcoal at 0, 50, and 100\% were able to sustain re-vegetation.

Treatment of opencast spoil with Fungcoal at 0, 50, and 100\%, together with a weathered coal co-substrate, did not appear to affect either substrate EC or CEC (Figure 4(c)). However, pH of substrate from the 50 and $100 \%$ Fungcoal treatments declined, albeit transiently, and this decline occurred coincident with onset of the summer hydrological cycle. Although recovery was gradual, substrate $\mathrm{pH}$ of the $50 \%$ Fungcoal treatment occurred more rapidly and was complete within 22 months.

Establishment of Digitaria eriantha, Chloris gayana, and Medicago sativa followed winter dieback of Eragrostis tef in 2013 to provide 100\% canopy cover in subsequent seasons where a weathered coal co-substrate had been applied to support Fungcoal, i.e. Kromdraai opencast (data not shown). One reason for the inability of Fungcoal in the absence of weathered coal to promote humic acid-like substance enrichment of substrate discard might be due to low or no buffering capacity. Substrate pH is an indicator of mineral balance whereas EC reflects the quantity of available minerals. Furthermore, excessive substrate EC usually indicates increased concentration of exchangeable ions and such substrates are characterised as poorly aggregated with low permeability; two factors that contribute unfavourable conditions for plant growth. Thus, EC of substrate from coal discard treated without co-substrate or with highly oxidised waste 
coal co-substrate is indicative of both high salinity and acidity which, in these examples, likely contributed to failure of seedling establishment and re-vegetation.

\section{Conclusion}

Fungcoal, a patented bioremediation process, was investigated to derive information for a protocol to ensure humic acid-like substance enrichment of discard and spoil and facilitate re-vegetation without the need for topsoil. Small-scale trials were used to qualify the contribution of sprigs and seed, substrate liming, AMF, and weathered coal as co-substrate for Neosartorya fischeri, to in situ humic acid-like enrichment of coal discard. Commercial-scale trials determined the extent to which Fungcoal-induced humic acid-like substance enrichment of the substrate depends on weathered coal as a co-substrate.

Results reported in this paper indicate that the current protocol used by South African coal mines to establish vegetation on disturbed land and coal discard dumps is appropriate. However, whether topsoil cladding and re-vegetation afford phyto-(bio)conversion and degradation of the underlying carbonaceous discard is unknown. Nevertheless, dependence on topsoil suggests that this protocol is unlikely to be sustainable and cost effective in the long run.

The present study also shows that application of the coal-degrading fungus Neosartorya fischeri together with AMF in the presence of weathered coal, i.e. Fungcoal, and without addition of topsoil, mitigates substrate acidification and salinity to provide conditions capable of supporting growth and establishment of annual and perennial plant species. Where no co-substrate was applied (i.e. Klippan) or where a highly oxidised waste coal co-substrate was used (i.e. Greenside), Fungcoal was unable to mitigate substrate acidification and salinisation. High substrate acidity is known to inhibit plant root growth and appears to do so by limiting nutrient availability (Kidd \& Proctor 2001; Zu et al. 2014). Thus, use of an appropriate carbon-rich co-substrate is crucial and appears to provide the buffering capacity needed for successful performance of the Fungcoal bioprocess technology. Similar findings have been reported for other coal degrading bioremediation processes (Juwarkar \& Jambhulkar 2008; Juwarkar et al. 2009).

\section{Acknowledgement}

This research was supported by a grant from Anglo American Coal South Africa and the National Research Foundation (IFR1202220169, Grant No: 80879). Ms. Lerato M. Sekhohola and Mr O. Gerald Edeki acknowledge financial support from Anglo American Coal South Africa in the form of doctoral bursaries. Dave Render, Yvonne van Breugel and Michelle Isaacs are thanked for assistance with sampling and Nomaindia Toto for laboratory analysis. The cooperation of mine personnel (Greenside, Kleinkopje and Landau Collieries) is appreciated.

\section{References}

Igbinigie, EE, Mutambanengwe, CZ \& Rose, PD 2010, 'Phyto-bioconversion of hard coal in the Cyanodon dactylon/coal rhizosphere', Biotechnology Journal, vol. 5, no. 5, pp. 292-303.

Igbinigie, EE, Aktins, S, Van Breugel, Y, Van Dyke, S, Davies-Coleman, MT \& Rose, PD 2008, 'Fungal biodegradation of hard coal by a newly reported isolate, Neosartorya fischeri', Biotechnology Journal, vol. 3, no. 11, pp. 1407-1416.

Janos, P 2003, 'Separation methods in the chemistry of humic substances', Journal of Chromatography A, vol. 983, pp. 1-18.

Juwarkar, AA \& Jambhulkar, HP 2008, 'Phytoremediation of coal mine spoil dump through integrated biotechnology approach', Bioresource Technology, vol. 99, no. 11, pp. 4732-4741.

Juwarkar, AA, Yadav, SK, Thawale, PR, Kumar, P, Singh, SK \& Chakrabarti, T 2009, 'Developmental strategies for sustainable ecosystem on mine spoil dumps: a case study', Environmental Monitoring and Assessment, vol. 157, no. 1-4, pp. 471-481.

Kidd, PS \& Proctor, J 2001, 'Why plants grow poorly on very acid soils: are ecologists missing the obvious?', Journal of Experimental Botany, vol. 52, no. 357, pp. 791-799.

Klein, OI, Kulikova, NA, Konstantinov, Al, Fedorova, TV, Landesman, EO \& Koroleva, OV 2013, 'Transformation of humic substastances of highly oxidized brown coal by Basidiomycetes Trametes hirsute and Trametes maxima', Applied Biochemistry and Microbiology, vol. 49, no. 3, pp. 287-295.

Laborda, F, Monistrol, IF, Luna, N \& Fernandez, M 1999, 'Processes of liquefaction/solubilization of Spanish coals by microorganisms', Applied Microbiology and Biotechnology, vol. 52, no. 1, pp. 49-56. 
Limpitlaw, D \& Briel, A 2015, 'Post-mining land use opportunities in developing countries-a review', The Journal of The Southern African Institute of Mining and Metallurgy, vol. 114, pp. 1-5.

Limpitlaw, D, Aken, M, Lodewijks, H \& Viljoen, J 2005, 'Post mining rehabilitation, land use and pollution at collieries in South Africa', in Proceedings of the colloquium: sustainable development in the life of coal mining, The Southern African Institute of Mining and Metallurgy, vol. 1, pp. 1-10.

Maiti, KS 2007, 'Bioreclamation of coalmine overburden dumps with special emphasis on micronutrients and heavy metals accumulation in tree species', Environmental Monitoring and Assessment, vol. 125, no. 1-3, pp. 111-122.

Mukasa-Mugerwa, TT, Dames, JF \& Rose, PD 2010, 'The role of a plant/fungal consortium in the degradation of bituminous hard coal', Biodegradation, vol. 1, pp. 1-13.

Rayment, GE \& Higginson, FR 1992, Australian Laboratory Handbook of Soil and Water Chemical Methods, Inkata Press, Melbourne. Rose, PD, Igbinigie, EE, Horan, MP, Dames, JF \& Mukasa-Mugerwa, TT 2010, 'Beneficiation of coal', South African Patent Office, ZA 2010/02354.

Ross, DS 1995, 'Recommended Methods for Determining Soil Cation Exchange Capacity', in JT Sims \& A Wolf (eds) Recommended Soil Testing Procedures for the Northeastern United States, 2nd edition, University of Delaware Press, Newark DE.

Ross, DS \& Ketterings, Q 2011, 'Recommended Methods for Determining Soil Cation Exchange Capacity', in A Wolf and J McGrath (eds), Recommended Soil Testing Procedures for the Northeastern United States, 3rd edition, Northeastern Regional Publication No. 493, http://ag.udel.edu/extension/agnr/soiltesting.htm

Salt, DE, Smith, RD \& Raskin, I 1998, 'Phytoremediation', Annual Review of Plant Physiology and Plant Molecular Biology, vol. 49, pp. 643-668.

Sekhohola, LM, Igbinigie, EE \& Cowan, AK 2013, 'Biological degradation and solubilisation of coal', Biodegradation, vol. 24, no. 3, pp. 305-318.

Sekhohola, LM, Isaacs, ML \& Cowan, AK 2014, 'Fungal colonization and enzyme-mediated metabolism of waste coal by Neosartorya fischeri strain ECCN 84', Bioscience, Biotechnology and Biochemistry, vol. 78, no. 10, pp. 1797-1802.

Sourkova, M, Frouz, J \& Santruckova, H 2005, 'Accumulation of carbon, nitrogen and phosphorus during soil formation on alder spoil heaps after brown-coal mining, near Sokolov (Czech Republic)', Geoderma, vol. 124, no. 1-2, pp. 203-214.

Zu, C, Li, Z, Yang, J, Yu, H, Sun, Y, Tang, H, Yost, R \& Wu, H 2014, 'Acid soil is associated with reduced yield, root growth and nutrient uptake in black pepper (Piper nigrum L.)', Agricultural Sciences, vol. 5, pp. 466-473. 
